\begin{abstract}
Background: A number of studies demonstrate that children who are younger within their school year have poorer academic attainment and are more likely to have special educational needs. Few, however, have considered the impact relative age may have on child mental health, behaviour and happiness in school.
\end{abstract}

Methods: This paper utilised data from the Supporting Teachers And ChildRen in Schools study (2075 pupils aged 5 to 9 years from 80 primary schools) to explore the relationship between relative age, behaviour and happiness in school. Behavioural and emotional development was assessed using the teacher and parent reported Strengths and Difficulties Questionnaire and the Pupil Behaviour Questionnaire. Children's happiness within school was assessed using the How I Feel About My School questionnaire.

Results: Relatively younger children had higher Total Difficulties scores on the Strengths and Difficulties Questionnaire than their peers. There was a mean increase per 30 day decrease in relative age of 0.09 (95\% CI: 0.03 to 0.16 ; $\mathrm{p}=0.007)$ in teacher-reported and $0.08(0.001$ to $0.16 ; \mathrm{p}=0.05)$ in parent-reported scores. There was little evidence of a relationship between relative age and children's behaviour and happiness in school.

Conclusions: For children with complex difficulties being relatively young for their school year may be an additional stressor that may undermine mental health.

This is the author manuscript accepted for publication and has undergone full peer review but has not been through the copyediting, typesetting, pagination and proofreading process, which may lead to differences between this version and the Version of Record. Please cite this article as doi: 10.1111/cch.12479

This article is protected by copyright. All rights reserved. 


\section{Examining the Psychological and Social Impact of Relative Age in Primary School Children: A Cross-Sectional Survey}

The youngest children in a school year may be nearly an entire year younger than their oldest peers. A number of studies have demonstrated that children born later in the school year are more likely to achieve lower scores in tests of academic attainment at primary (McPhillips \& Jordan-Black, 2009; Sharp, Hutchinson, \& Whetton, 1994) and secondary school (Cobley, McKenna, Baker, \& Wattie, 2009), be overrepresented within lower ability streaming groups (D. Thompson, 1971) and be identified as having special educational needs (SEN) (Gledhill, Ford, \& Goodman, 2002; Wilson, 2000). These 'relative age effects' can impact on a child's future education and career prospects. As similar effects have been detected in countries with different school entry cut-off dates, it would seem that relative age rather than season of birth is the driving influence (Goodman, Gledhill, \& Ford, 2003). Indeed, the scores of relatively young children did not differ significantly from their older peers on age-standardised measures of attainment in the British Child and Adolescent Mental Health Survey 1999 (Goodman et al., 2003). These findings have led to the UK Department of Education reviewing the guidance on school admissions to allow parents to defer their child's entry to school by one year if they are born in the summer (Department for Education, 2014a). Despite evidence supporting the link between relative age and academic attainment, the policy changes about school entry in the UK and the increasing focus of schools on mental health issues described below (Department for Education, 2014b; Institute for Public Policy Research, 2016; Parker et al., 2016), few studies have considered the impact relative age may also have on a child's mental health and well-being in school. 
Child psychopathology, well-being and happiness have been a key focus for a number of school based initiatives worldwide including programmes such as the Healthy Schools Programme (Warwick, Mooney, \& Oliver, 2009) and the Social and Emotional Aspects of Learning (SEAL) Programme (Hallam, 2009). Disruptive behaviour is the most common type of childhood psychiatric disorder in the school age population (BCAMHS 1999 and 2004) and is strongly associated with stress, burn out and exit from the profession among teachers as well as disrupting the learning of all in the classroom (Aloe, Shisler, Norris, Nickerson, \& Rinker, 2014; Tsouloupas, Carson, Matthews, Grawitch, \& Barber, 2010; Wharton, 2009). Teachers feel very torn between supporting individual children whose poor mental health impedes their ability to cope in the classroom and their duty to the rest of the class (Richardson et al., 2015). Poor mental health and disruptive behaviour is an accepted impediment to learning and has been linked to a number of adverse outcomes later in life including conduct disorder, anti-social behaviour, crime, substance misuse, educational failure and violence (Collishaw, Maughan, Goodman, \& Pickles, 2004). Such adverse sideaffects not only present during childhood but also persist throughout adolescence, leading to poor future prospects and high costs to society (Scott, Knapp, Henderson, \& Maughan, 2001). Using a combination of psychological distress based on scores on the Strengths and Difficulties Questionnaire (SDQ) (Goodman, 2001) and psychiatric interviews in a large population based sample, Goodman et al. (2003) reported that children who were younger within their school year had poorer mental health than their relatively older peers. Similarly, in a large sample of African American and European American children, the prevalence of psychiatric disorders was higher among children who were youngest within their academic 
year (Polizzi, Martin, \& Dombrowski, 2007). Patalay et al. (2015) also found that relatively younger adolescents had more emotional symptoms and peer problems when compared with relatively older peers using SDQ data from a large population-based sample (born 19961998).

Studies in North America, Sweden and Canada have also indicated relatively younger children in school are more likely to have received a diagnosis of, and receive a prescription for, attention deficit hyperactivity disorder (ADHD) (Elder, 2010; Halldner et al., 2014; Marrow et al., 2012). Goodman et al. (2003)' study is unique in that it considers psychopathology in general, but the data were collected in 1999 and, as there have been numerous changes in policy and practice (e.g., free part-time early years' education) since, they may not reflect children's experiences now.

Within adults there is a known relationship between "happiness", an affective component of well-being, and cognitive functions which can influence learning. For example, Fredrickson and Branigan (2005) found that positive versus neutral affect was associated with increased attention and cognition and others have found positive affect may also help increase creative (Isen, Daubman, \& Nowicki, 1987) and holistic thinking (Isen, Rosenzweig, \& Young, 1991). There are indications that relatively young children may be more unhappy at school (see Crawford, Dearden, \& Greaves, 2011), be more likely to be bullied (Department for Education, 2010), have lower levels of self-esteem (Fenzel, 1992; A. Thompson, Barnsley, \& Battle, 2004) and commit suicide (Thompson et al 1999) than their older peers. However, to our knowledge, few studies have considered the impact that being 
young relative to others in your class may have on a child's happiness, particularly happiness at school.

The objective of the current study was to explore the relationship of relative age with child mental health, behaviour and happiness in school (hereafter referred to as 'happiness') in a large sample of primary school children aged 4 to 9 years old. We predicted that relatively younger children would (a) have poorer mental health, (b) be more disruptive than their older peers and (c) be less happy.

\section{Method}

This paper presents an analysis of baseline data from the Supporting Teachers And ChildRen in Schools (STARS) study, a cluster randomised controlled trial of the Incredible Years Teacher Classroom Management (TCM) programme (Ford et al., 2012). Ethical approval for the study was granted by Peninsula College of Medicine and Dentistry Research Ethics Committee, now University of Exeter Medical School.

\section{Participants}

The sample comprised 2075 children (out of 2188 eligible) aged 4 to 9 years from 80 schools in Devon, UK. Eligible schools were state-funded mainstream primary schools. Schools placed in special measures by Ofsted were excluded. Devon has a predominantly White British (93.5\%) population with areas of high deprivation (Devon County Council, 2013). Participating schools were from a mixture of urban (54\%) and non-urban locations; $18 \%$ located in a deprived area (lowest quintile according to the Index of Multiple 
Deprivation (IMD)) (McLennan et al., 2011). More than half of schools (58\%) had higher than the English mean proportion of children eligible to receive free school meals (Department for Education, 2012).

\section{Procedure}

Parents had two weeks to opt themselves and their child out of the trial; teachers provided written consent and children verbal assent. Data was collected during the first half of the autumn term in 2013 (15 schools), 2014 (30 schools) and 2015 (35 schools). Children in Foundation (ages 4-5) and Key Stage 1 (KS1) (ages 5-7) were given one-to-one support to complete the How I Feel About My Schools Questionnaire (see below) while children in Key Stage 2 (KS2) (ages 7-9) completed it as a class-based activity. Parents received paper questionnaires while teachers and special educational needs coordinators used a web-based electronic database. Parents and teachers were thanked for completing measures by receiving a $£ 5$ or $£ 20$ gift voucher respectively.

\section{Outcome Measures}

Mental health was assessed using teacher and parent versions of the SDQ (Goodman, 1997). The SDQ comprises 25 items that span five sub-scales (behaviour, emotions, overactivity/concentration, peer relationships and pro-social behaviour); respondents answer a mixture of positively- and negatively-worded statements on a three-point Likert scale (not true (0), somewhat true (1) or certainly true (2)). The 20 items in the first four sub-scales are summed to give a total difficulties score (range 0-40), with higher scores indicating greater difficulties (Goodman, 1997, 2001). The SDQ is a brief, valid and reliable measure (internal 
consistency, Cronbach's alpha $(\alpha)=0.73$; cross-informant correlation, Pearson's correlation $(r)=0.34$; test-retest stability after four to six months, $\alpha=0.62)$ and is widely used to assess mental health in childhood.

Children's behaviour in school. The Pupil Behaviour Questionnaire $(P B Q)$ was developed for STARS (Ford et al., 2012) and was adapted from a scale used extensively in school effectiveness studies (Gray, Richer, Team, \& Group, 1988). Teachers answered questions measuring classroom behaviours such as talking out of turn or making rude remarks. Responses to the six items are on a three-point Likert scale of never (0), occasionally (1) or frequently (2), with higher scores (range 0-12) indicating more disruptive behaviour. The PBQ has good internal consistency (Cronbach's $\alpha=0.86$ ) with factor analysis confirming a one factor structure, indicating all six questions measure the same dimension (Allwood \& Ford, in preparation). There is preliminary evidence of validity, with a moderate convergence between the PBQ and teacher-completed SDQ Total Difficulties scores and Conduct sub-scale (Spearman's correlation coefficient $\left(r_{s}\right)=0.43$ and 0.45 respectively) (Allwood \& Ford, in preparation).

Children's happiness in the school context. This was measured by the How I Feel About My School (HIFAMS) questionnaire, which was also developed for use in the STARS study (Ford et al., 2012). This measure includes seven questions about how children feel about their school, relationships with their peers, teacher and learning. Answers are on a three-point Likert scale, with emoticons indicating sad (0), OK (1), and happy (2). Higher scores indicate greater happiness at school (range 0-14). Allen et al. (2017) found HIFAMS 
demonstrated adequate two week test-retest reliability (Spearman's correlation $\left(r_{s}\right)=0.62$; 95\% CI: 0.54 to 0.69 ) and moderate internal consistency (Cronbach's $\alpha=0.62$ ).

\section{Other Measures}

Assessing Pupils' Progress (APP). The APP is an assessment tool used to measure children's attainment in literacy and numeracy in English schools, to enable professionals to track progress against nationally agreed criteria (Department for Children, 2009). Teacher reported attainment levels for each child were compared with the level expected by an average child in their year group. Results were categorised as Working Below Age-Related Expectations or At/Above Exact Age-related Expectations.

Special educational needs (SEN). Special educational needs coordinators reported whether a child had any recognised SEN, or extra support.

Demographic characteristics. Alongside child age and gender, parents were asked to indicate their own educational level (any qualifications versus none) and describe their current housing situation (home owner versus not) (Ford et al., 2012). Children's postcodes, where available, indicated whether they lived in an area categorised as in the lowest quintile based on the Index of Multiple Deprivation.

\section{Statistical Analysis}

Statistical analyses were conducted using Stata software, version 13.

Study measures were summarised for all children and by relative age category. Sample characteristics were compared against Devon norms. 
The main analyses examined the relationship between Relative Age (predictor variable) and each of the following outcomes: mental health (teacher and parent SDQ Total Difficulties score), disruptive behaviour (PBQ) and happiness (HIFAMS) using random effects linear regression, specifying school as a random effect. This method allows for the correlation between the responses of pupils within schools (clusters). Relative age was rescaled in such a manner that the regression coefficient is the estimated mean increase in the continuous outcomes per 30 day decrease in relative age. Relative age was used as a categorical variable when summarising the data with three levels defined by the child's month of birth (Oldest (September to December), Middle (January to April), and Youngest (May to August)).

Crude (unadjusted) analyses and analyses adjusted for potential confounders (gender, SES and year group) were run. The regression results reported are based on the analyses of 20 multiply imputed datasets in which missing values were filled in, with the assumption that data were missing at random. Data were imputed using the chained equations (fully conditional specification) method (Royston, 2004) with all study variables (outcomes, relative age, potential confounders and mediators) included in the imputation model. Analyses of imputed data provided essentially the same results as those from complete case analyses. The mi impute Stata command was used to impute missing data and mi estimate to analyse the imputed datasets.

This article is protected by copyright. All rights reserved. 


\section{Results}

\section{Descriptive Results}

Teachers, children and parents provided data on $100 \%, 98 \%$ and $70 \%$ of the sample respectively. The median (interquartile range; range) number of children per school was 27 (24 to $28 ; 17$ to 33 ). Table 1 reports characteristics of recruited children. Numbers of children with SEN and those in the lowest quintile for the Index of Multiple Deprivation were representative of Devon, but SEN levels were slightly higher than the percentage for England (18.5\%) (Department for Education, 2012). Just over half of children had below average APP literacy and numeracy scores, as expected for an assessment at the beginning of the school year. Mean teacher reported SDQ Total Difficulties scores were lower for children whose parents completed the parent questionnaire (6.2) than for those whose parents did not (7.9).

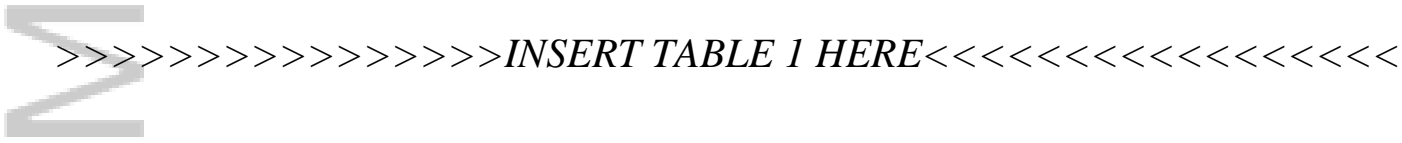

A higher percentage of relatively young children had SEN or extra support compared with their older peers and were reported to be below average on the APP literacy and numeracy measures (see Table 1).

Responses across all outcome measures indicated that overall children had low levels of disruptive behaviour and high scores for happiness. Similarly SDQ Total Difficulties scores were similar to those for the primary school population within Great Britain (mean 
teacher 6.7 and parent 8.6 scores (see http://www.sdqinfo.org/)) as expected for a sample selected from mainstream education (see Table 2).

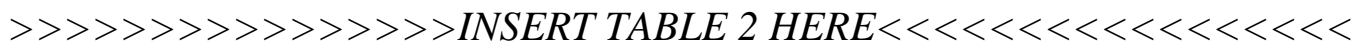

\section{Relative Age as a Predictor of Happiness, Mental Health and Behaviour}

Relatively young children had marginally higher SDQ Total Difficulties scores as reported by teachers and parents compared to their older peers (see Table 3). On average, an 8 month difference in relative age resulted in the younger children (born later in the academic year) having SDQ Total Difficulties scores that were higher by 0.74 points (as reported by teachers) and 0.64 points (as reported by parents). However, no differences were found between relatively younger and older children on the behavioural (PBQ) and happiness (HIFAMS) outcomes.

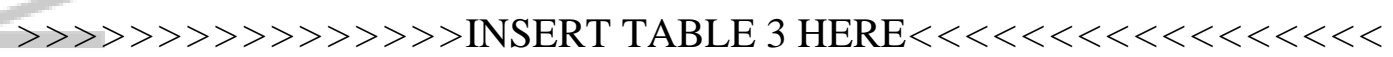

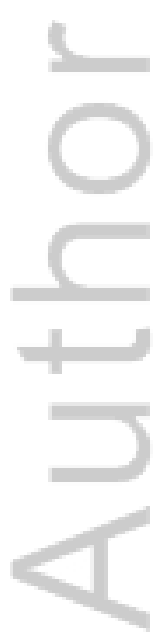

This article is protected by copyright. All rights reserved. 


\section{Discussion}

The current study found a statistically significant relationship between relative age and children's mental health, albeit of low strength. Relative age was not, as we initially predicted, associated with behaviour or happiness. Below, we explore our findings in the context of the existing literature and their implications for policy and practice, and consider the strengths and limitations of the data.

The effect of relative age tends to be most evident in activities that are "characterised by age grouping, competition and selection ability” (A. Thompson et al., 2004 p314), components that are all present in the education environment. Children who are relatively young within their academic year were more likely to score higher on a well-established measure of child mental health, the SDQ, but at group level, the differences were such that they would be unlikely to make a difference in isolation at an individual level. Our findings do replicate other studies (Crawford et al., 2011; Ford, Goodman, \& Meltzer, 2003; Patalay et al., 2015), which implies there may be a number of relatively young children for whom the additional stress of trying to keep up with older, more developmentally advanced children at school may compound other adversities. Relative age may become more important when there are other challenges to mental health and learning.

The absence of a strong relationship between relative age and child mental health at a group level may reflect an increased focus on social and emotional wellbeing in UK schools during the early years of this century. For example, there has been a substantial increase in the entitlement to free early years education (Brewer, Cattan, Crawford, \& Rabe, 2014), 
increased emphasis on the foundation stage (Department for Education, 2014c) and an increase in well-being initiatives within schools (e.g. Department for Education and Schools, 2004; Department for Children, 2007). It is possible such changes may limit the impact of relative age on mental health, despite its continuing effect on perceived academic attainment and SEN status.

In contrast to our findings, previous studies have found that relative age can impact on behavioural problems (Norbury et al., 2015) and conditions such as ADHD. The PBQ focuses on low level classroom disruption, such as talking to peers, rather than general behaviour problems (lying, stealing) and does not measure core symptoms of ADHD. This was a surprising finding as we anticipated that relatively young children would struggle more than their older peers to meet the behavioural expectations of the classroom.

Similarly, we found no evidence that happiness at primary school was affected by relative age. Previous research has suggested that relatively young children are more likely to have lower levels of self-esteem (Fenzel, 1992; A. Thompson et al., 2004), be bullied at school (Department for Education, 2010) and commit suicide (A. Thompson, Barnsley, \& Dyck, 1999), which could plausibly be associated with unhappiness. Additionally, Patelay et al. (2015) found of a small but significant effect of relative age on the emotional symptoms sub-scale of the SDQ in students aged 11-13 years. Children may not experience an emotional effect of relative age in school until they are older than our sample (4-9 years) and more able to compare themselves with others. More research is needed to clarify the impact of relative age on happiness and emotional difficulties in school children of different ages. 
Recent changes in policy that may reduce or amplify the effect of relative age, such as allowing parents to defer their summer-born child's entry to school by a year in England (Department for Education, 2014a), should be closely monitored. Education and mental health practitioners should be aware that relative age may be an additional risk factor for those struggling with multiple difficulties, but our findings suggest that it is unlikely to significantly affect an individual child's mental health in isolation.

Our study has several strengths. It is one of the first to investigate the impact of relative age on children's happiness in school. The combination of a large sample with wellvalidated and reliable measures of child mental health allow us to confidently assert the current impact of relative age on child mental health among primary schools in Devon. We found the expected relationships between relative age and academic attainment and SEN status, which suggests that our unexpected results in relation to behaviour and happiness were findings that were not solely due to unusual characteristics of our sample.

However, given that participants were recruited from South West England, our results may not generalise to other areas, particularly those with high numbers of children from ethnic minority groups. While return rates for teacher-reported (100\%) and child-reported (98\%) measures were excellent, we only had parent SDQ scores for $70 \%$ of the sample. Teacher reports suggest that children whose parents did not return questionnaires were likely to experience poorer mental health. Multiple imputations allowed us to fill in missing data. In addition, previous research suggests that despite the inevitable loss of those living in deprivation and with poorer health from child mental health research, the pattern of association will not necessarily have been altered (Wolke et al., 2009). Finally, our data were 
cross-sectional and it may be that the impact of the detected differences in attainment, SEN status and mental health might have led to later difficulties with behaviour and unhappiness. Alternatively, as the developmental variation between the youngest and oldest in the school year might be expected to narrow with age, these differences might be expected to reduce over time.

= In summary, we found that relative age has a small but significant association with children's mental health but does not impact young children's behaviour and happiness at school. Future research is needed to further explore the developmental trajectory of relatively young children in terms of their behaviour and happiness longitudinally, among older school children and across different geographic locations.

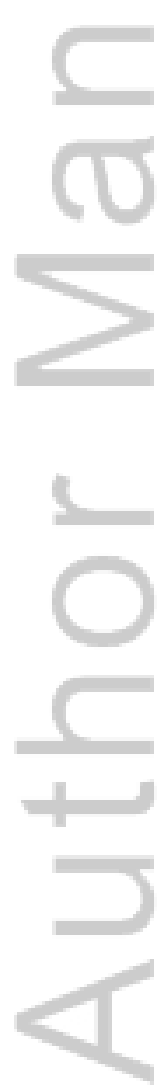

This article is protected by copyright. All rights reserved. 
Key Practitioner Message:

- This study suggests that children who are born later in the academic year, and are therefore relatively younger than their peers, have poorer mental health as rated by teachers and parents.

- In keeping with previous studies, findings showed population level effects on child mental health by relative age, but these average differences were too small to be clinically significant in isolation at an individual level.

- We found little evidence of a relative age effect on child reported happiness or teacher reported low level disruptive behaviour in school.

- For children with multiple challenges, relative age may be an additional stressor that could undermine mental health and is therefore worth considering when undertaking assessments.

- Parents deferring their summer-born child's entry to school by a year are likely to circumvent the negative impact of relative age on mental health. 


\section{References}

Allen, K., Marlow, R., Edwards, V., Parker, C., Rodgers, L., Ukoumunne, O. C., Chan Seem, E., Hayes, R., Price, A., \& Ford, F. (2017) 'How I feel About My School': the construction and validation of a novel measure of wellbeing at school for primary school children. Clinical Child Psychology and Psychiatry, 1-17. doi: 10.1177/1359104516687612.

Allwood, M. \& Ford, T. (in preparation) Validity and reliability of the pupil behaviour questionnaire; a child classroom behaviour assessment tool. BSc Medical Sciences.

Aloe, A. M., Shisler, S. M., Norris, B. D., Nickerson, A. B., \& Rinker, T. W. (2014) A multivariate meta-analysis of student misbehavior and teacher burnout. Educational Research Review, 12, 30-44.

Brewer, M., Cattan, S., Crawford, C., \& Rabe, B. (2014) The impact of free early education for 3 year olds in England. Retrieved from https://www.ifs.org.uk/uploads/publications/docs/MISOC\%20Childcare\%20briefing \%20paper.pdf

Cobley, S., McKenna, J., Baker, J., \& Wattie, N. (2009) How pervasive are relative age effects in secondary school education? Journal of Educational Psychology, 101, 520-528. doi:10.1037/A0013845

Collishaw, S., Maughan, B., Goodman, R., \& Pickles, A. (2004) Time trends in adolescent mental health. Journal of Child Psychology and Psychiatry, 45, 1350-1362.

This article is protected by copyright. All rights reserved. 
Crawford, C., Dearden, L., \& Greaves, E. (2011) Does when you are born matter? The impact of month of birth on children's cognitive and non-cognitive skills in England.

Retrieved from https://www.ifs.org.uk/bns/bn122.pdf

Department for Children, Schools and Families. (2009) Getting to Grips with Assessing Pupils' Progress. Nottingham: Department for Children, Schools and Families Retrieved from http://webarchive.nationalarchives.gov.uk/20130401151715/http://www.education .gov.uk/publications/eOrderingDownload/Assessing_pupils_progress.pdf

Department for Education. (2010) Month of birth and education: schools analysis and research division. Manchester: Department for Education.

Department for Education. (2012) Schools, pupils and their characteristics: January 2012. London: Department for Education Retrieved from https://www.gov.uk/government/uploads/system/uploads/attachment data/file/21 9260/sfr10-2012.pdf.

Department for Education. (2014a) Advice on the admission of summer born children: for local authorities, school admission authorities and parents. London: Department for Education Retrieved from https://www.gov.uk/government/uploads/system/uploads/attachment data/file/38 9448/Summer born_admissions advice Dec 2014.pdf.

Department for Education. (2014b) Mental Health and Behaviour in Schools. London:

Department for Education Retrieved from

This article is protected by copyright. All rights reserved. 
https://www.gov.uk/government/uploads/system/uploads/attachment data/file/50 8847/Mental Health and Behaviour - advice for Schools 160316.pdf.

Department for Education. (2014c) Statutory framework for the early years foundation stage: setting the standards for learning, development and care for children from birth to five. London: Department for Education.

Devon County Council. (2013) Joint Strategic Needs Assessment Devon Overview 2013. Retrieved from http://www.devonhealthandwellbeing.org.uk/wpcontent/uploads/2013/12/JSNA-Devon-Overview-2013.pdf

Elder, T. E. (2010) The importance of relative standards in ADHD diagnoses: evidence based on exact birth dates. Journal of Health Economics, 29, 641-656. doi:10.1016/j.jhealeco.2010.06.003

Fenzel, L. M. (1992) The Effect of Relative Age on Self-Esteem, Role Strain, GPA, and Anxiety. The Journal of Early Adolescence, 12, 253-266. doi:10.1177/0272431692012003002

Ford, T., Edwards, V., Sharkey, S., Ukoumunne, O., Byford, S., Norwich, B., \& Logan, S. (2012) Supporting teachers and children in schools: the effectiveness and cost-effectiveness of the incredible years teacher classroom management programme in primary school children: a cluster randomised controlled trial, with parallel economic and process evaluations. BMC Public Health, 12, 719. doi:10.1186/1471-2458-12-719

Ford, T., Goodman, R., \& Meltzer, H. (2003) The British Child and Adolescent Mental Health Survey 1999: the prevalence of DSM-IV disorders. Journal of the American Academy 
of Child and Adolescent Psychiatry, 42, 1203-1211. doi:10.1097/00004583200310000-00011

Fredrickson, B. L., \& Branigan, C. (2005) Positive emotions broaden the scope of attention and thought-action repertoires. Cognition and Emotion, 19, 313-332.

doi:10.1080/02699930441000238

Gledhill, J., Ford, T., \& Goodman, R. (2002) Does season of birth matter?: The relationship between age within the school year (season of birth) and educational difficulties among a representative general population sample of children and adolescents (aged 5-15) in Great Britain. Research in Education, 68, 41-47. doi:10.7227/RIE.68.4 Goodman, R. (1997) The Strengths and Difficulties Questionnaire: a research note. Journal of child psychology and psychiatry, 38, 581-586. doi:10.1111/j.14697610.1997.tb01545.x/pdf

Goodman, R. (2001) Psychometric properties of the strengths and difficulties questionnaire (SDQ). Journal of the American Academy of Child and Adolescent Psychiatry, 40, 1337-1345. doi:10.1097/00004583-200111000-00015

Goodman, R., Gledhill, J., \& Ford, T. (2003) Child psychiatric disorder and relative age within school year: cross sectional survey of large population sample. British Medical Journal, 327, 472-475. doi:10.1136/bmj.327.7413.472

Gray, J., Richer, J., Team, S. N. R., \& Group, O. E. R. (1988) Classroom responses to disruptive behaviour. London: Macmillan Education.

This article is protected by copyright. All rights reserved. 
Hallam, S. (2009) An evaluation of the Social and Emotional Aspects of Learning (SEAL) programme: promoting positive behaviour, effective learning and well-being in primary school children. Oxford Review of Education, 35, 313-330.

Halldner, L., Tillander, A., Lundholm, C., Bomen, M., Långström, N., Larsson, H., \& Lichtenstein, P. (2014) Relative immaturity and ADHD: findings from nationwide registers, parent- and self-reports. Journal of Child Psychology and Psychiatry, 55, 897-904. doi:10.1111/jcpp.12229

Institute for Public Policy Research. (2016) Education, education, mental health: Supporting secondary schools to play a central role in early intervention mental health services. London Retrieved from http://www.ippr.org/files/publications/pdf/educationeducation-mental-health May2016.pdf?noredirect=1.

Isen, A. M., Daubman, K. A., \& Nowicki, G. P. (1987) Positive affect facilitates creative problem solving. Journal of Personality and Social Psychology, 52, 1122-1131. doi:10.1037/0022-3514.52.6.1122

Isen, A. M., Rosenzweig, A. S., \& Young, M. J. (1991) The influence of positive affect on clinical problem solving. Medical Decision Making, 11, 221-227. doi:10.1177/0272989X9101100313

Marrow, R. L., Garland, J., Wright, J. M., Maclure, M., Taylor, S., \& Dormuth, C. R. (2012) Influence of relative age on diagnosis and treatment of attentiondeficit/hyperactivity disorder in children. Canadian Medical Association Journal, 184, 755-762. doi:10.1503/cmaj.111619 
McLennan, D., Barnes, H., Noble, M., Davies, J., Garratt, E., \& Dibben, C. (2011) The English indices of deprivation 2010. London: Department for Communities and Local Government.

McPhillips, M., \& Jordan-Black, J. A. (2009) The effect of month of birth on the attainments of primary and secondary school pupils. British Journal of Educational Psychology, 79, 419-438. doi:10.1348/978185408×380199

Norbury, C. F., Gooch, D., Baird, G., Charman, T., Simonoff, E., \& Pickles, A. (2015) Younger children experience lower levels of language competence and academic progress in the first year of school: evidence from a population study. The Journal of Child Psychology and Psychiatry. doi:10.1111/jcpp.12431

Parker, C., Marlow, R., Kastner, M., May, F., Mitrofan, O., Henley, W., \& Ford, T. (2016) The 'Supporting Kids, avoiding Problems'(SKIP) study: relationships between school exclusion, psychopathology, development and attainment-a case control study. Journal of Childrens Services, 11, 91-110.

Patalay, P., Belsky, J., Fonagy, P., Vostanis, P., Humphrey, N., Deighton, J., \& Wolpert, M. (2015) The Extent and Specificity of Relative Age Effects on Mental Health and Functioning in Early Adolescence. Journal of Adolescent Health, 57, 475-481. doi:http://dx.doi.org/10.1016/j.jadohealth.2015.07.012

Polizzi, N., Martin, R. P., \& Dombrowski, S. C. (2007) Season of birth of students receiving special education services under a diagnosis of emotional and behavioral disorder. School Psychology Quarterly, 22, 44-57. doi:10.1037/1045-3830.22.1.44

This article is protected by copyright. All rights reserved. 
Richardson, M., Moore, D. A., Gwernan-Jones, R., Thompson-Coon, J., Ukoumunne, O. C., Rogers, M., Whear, R., Newlove-Delgado, T. V., Logan, S., \& Morris, C. (2015) Nonpharmacological interventions for attention-deficit/hyperactivity disorder (ADHD) delivered in school settings: systematic reviews of quantitative and qualitative research. Health Technology Assessment, 19.

Royston, P. (2004) Multiple imputation of missing values. Stata Journal, 4, 227-241.

Scott, S., Knapp, M., Henderson, J., \& Maughan, B. (2001) Financial costs of social exclusion: follow up study of antisocial children into adulthood. British Medical Journal, 323, 191-195.

Sharp, C., Hutchinson, D., \& Whetton, C. (1994) How do season of birth and length of schooling affect children's attianment at key stage 1? Educational Research, 36, 107121. doi:10.1080/0013188940360201

Thompson, A., Barnsley, R., \& Battle, J. (2004) The relative age effect and the development of self-esteem. Educational Research, 46, 313-320. doi:10.1080/0013188042000277368

Thompson, A., Barnsley, R. H., \& Dyck, R. J. (1999) A new factor in youth suicide: the relative age effect. Canadian Journal of Psychiatry, 44, 82-85.

Thompson, D. (1971) Season of birth and success in secondary school. Educational Research, 14, 56-60. doi:10.1080/0013188710140107

Tsouloupas, C. N., Carson, R. L., Matthews, R., Grawitch, M. J., \& Barber, L. K. (2010) Exploring the association between teachers' perceived student misbehaviour and 
emotional exhaustion: The importance of teacher efficacy beliefs and emotion regulation. Educational Psychology, 30, 173-189.

Warwick, I., Mooney, A., \& Oliver, C. (2009) National Healthy Schools Programme: developing the evidence base. University of London: Institute of Education.

Wharton, A. S. (2009) The sociology of emotional labor. Annual review of sociology, 35, 147-

165.

Wilson, G. (2000) The effects of season of birth, sex and cognitive abilities on the assessment of special needs. Journal of Educational Psychology, 20, 153-166. doi:10.1080/713663714

Wolke, D., Waylen, A., Samara, M., Steer, C., Goodman, R., Ford, T., \& Lamberts, K. (2009) Selective drop-out in longitudinal studies and non-biased prediction of behaviour disorders. The British Journal of Psychiatry, 195, 249-256.

doi:10.1192/bjp.bp.108.053751

Table 1 Sample Characteristics by Relative Age

This article is protected by copyright. All rights reserved. 
$\underline{\text { All }^{\mathrm{a}}} \quad \underline{\text { Relative Age }}$

Characteristic

Oldest $^{\mathrm{b}} \quad$ Middle $^{\mathrm{c}} \quad$ Youngest $^{\mathrm{d}}$

\begin{tabular}{lccccc}
\hline Age, mean (SD) & $6.8(1.3)$ & & $7.1(1.3)$ & $6.8(1.3)$ & $6.4(1.3)$ \\
Male, \% & 53.1 & & 54.2 & 53.8 & 51.2 \\
White British, \% & 95.1 & & 94.1 & 95.9 & 95.1 \\
Key stage 2, \% & 49.5 & & 45.8 & 51.3 & 51.5 \\
Parent any qualification, \% & 95.0 & & 93.2 & 94.8 & 96.9 \\
Homeowners, \% & 60.2 & & 61.8 & 53.7 & 65.2 \\
In the lowest 20\% of SES, \% & 16.3 & & 17.0 & 16.7 & 15.2 \\
SEN or extra support, \% & 21.3 & & 17.1 & 22.7 & 24.1 \\
Below average APP literacy, \% & 60.7 & & 52.4 & 60.7 & 69.0 \\
Below average APP numeracy, \% & 53.8 & & 45.2 & 53.2 & 62.9 \\
\hline
\end{tabular}

${ }^{\mathrm{a}} \mathrm{N}$ ranges from 1403 to $2075,{ }^{\mathrm{b}} \mathrm{N}$ ranges from 466 to $701,{ }^{\mathrm{c}} \mathrm{N}$ ranges from 465 to $671,{ }^{\mathrm{d}} \mathrm{N}$ ranges from 485 to 703

$\mathrm{SES}=$ Socio Economic Status, SEN = Special Educational Needs, APP = Assessing Pupils' Progress 
Table 2 Outcome Variable Characteristics by Relative Age

\begin{tabular}{|c|c|c|c|c|}
\hline \multirow[b]{2}{*}{ Outcome Variable } & \multirow{2}{*}{$\begin{array}{c}\underline{\text { All }}^{\mathrm{a}} \\
\text { Mean } \\
(\mathrm{SD})\end{array}$} & \multicolumn{3}{|c|}{$\underline{\text { Relative Age }}$} \\
\hline & & Oldest $^{\mathrm{b}}$ & Middle $^{c}$ & Youngest $^{\mathrm{d}}$ \\
\hline $\begin{array}{l}\text { SDQ Total Difficulties teacher } \\
\text { reported }\end{array}$ & $6.7(5.9)$ & $6.4(5.8)$ & $6.9(6.0)$ & $6.8(5.7)$ \\
\hline $\begin{array}{l}\text { SDQ Total Difficulties parent } \\
\text { reported }\end{array}$ & $7.0(5.6)$ & $6.6(5.5)$ & $7.6(6.1)$ & $7.0(5.2)$ \\
\hline PBQ child behaviour in school & $1.9(2.4)$ & $2.0(2.5)$ & $1.9(2.5)$ & $1.9(2.3)$ \\
\hline $\begin{array}{l}\text { HIFAMS child happiness in } \\
\text { school }\end{array}$ & $11.0(2.4)$ & $11.0(2.3)$ & $1.0(2.4)$ & $11.0(2.4)$ \\
\hline
\end{tabular}

${ }^{\mathrm{a}} \mathrm{N}$ ranges from 1403 to $2075,{ }^{\mathrm{b}} \mathrm{N}$ ranges from 466 to $701,{ }^{\mathrm{c}} \mathrm{N}$ ranges from 465 to $671,{ }^{\mathrm{d}} \mathrm{N}$ ranges from 485 to 703

SDQ = Strengths and Difficulties Questionnaire, PBQ = Pupil Behaviour Questionnaire, HIFAMS = How I Feel About My School questionnaire 
Table 3 Linear Regression Analysis to independent association between child mental health, behaviour and happiness with Relative Age (Coefficients Indicate Mean Change Per 30 Day Decrease in RA)

\begin{tabular}{|c|c|c|c|c|}
\hline \multirow[b]{2}{*}{ Outcome Variable } & Unadjusted regression $^{a}$ & \multicolumn{3}{|c|}{ Adjusted regression ${ }^{\mathrm{a}, \mathrm{b}}$} \\
\hline & Coeff. & Coeff. & $95 \% \mathrm{CI}$ & $\mathrm{p}$ \\
\hline $\begin{array}{l}\text { Teacher reported SDQ Total } \\
\text { Difficulties }\end{array}$ & 0.08 & 0.09 & 0.03 to 0.16 & 0.007 \\
\hline $\begin{array}{l}\text { Parent reported SDQ Total } \\
\text { Difficulties }\end{array}$ & 0.07 & 0.08 & 0.001 to 0.16 & 0.05 \\
\hline PBQ child behaviour in school & 0.0003 & 0.004 & -0.02 to 0.03 & 0.76 \\
\hline HIFAMS child happiness in school & -0.0003 & -0.0001 & -0.03 to 0.03 & 0.92 \\
\hline
\end{tabular}

Coeff = regression coefficient CI = Confidence Interval; ${ }^{\mathrm{a}} \mathrm{N}=2075 ;{ }^{\mathrm{b}}$ adjusted for gender, homeowner status and year group SDQ = Strengths and Difficulties Questionnaire, PBQ $=$ Pupil Behaviour Questionnaire, HIFAMS = How I Feel About My School questionnaire

This article is protected by copyright. All rights reserved. 


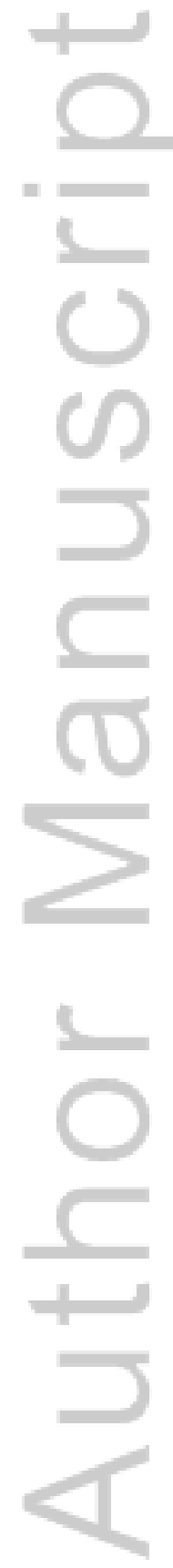

This article is protected by copyright. All rights reserved. 


\section{University Library}

\section{- M M N E R VA A gateway to Melbourne's research publications}

Minerva Access is the Institutional Repository of The University of Melbourne

Author/s:

Price, A;Allen, K;Ukoumunne, OC;Hayes, R;Ford, T

Title:

Examining the psychological and social impact of relative age in primary school children: a cross-sectional survey

Date:

2017-11-01

Citation:

Price, A., Allen, K., Ukoumunne, O. C., Hayes, R. \& Ford, T. (2017). Examining the psychological and social impact of relative age in primary school children: a crosssectional survey. CHILD CARE HEALTH AND DEVELOPMENT, 43 (6), pp.891-898. https:// doi.org/10.1111/cch.12479.

Persistent Link:

http://hdl.handle.net/11343/292938 